\title{
Evaluation of bearing, gears and gearboxes performance with different wind turbine gear oils
}

\author{
Ramiro Carneiro MARTINS ${ }^{1, *}$, Carlos M. C. G. FERNANDES ${ }^{1}$, Jorge H. O. SEABRA ${ }^{2}$ \\ ${ }^{l}$ INEGI, Universidade do Porto, Porto, Portugal \\ ${ }^{2}$ Faculdade de Engenharia, Universidade do Porto, Porto, Portugal \\ Received: 16 April 2015 / Revised: 15 August 2015 / Accepted: 09 November 2015 \\ (C) The author(s) 2015. This article is published with open access at Springerlink.com
}

\begin{abstract}
The oil viscosity specification for wind turbine gear oils is ISO VG 320, although there are quite different viscosity indexes oils for that viscosity specification. This work evaluates the behaviour of different base oil formulations, since polyalphaolefin (PAO), mineral, ester and polyalkeleneglycol (PAG) that withstand quite different viscosity indexes. The oils evaluation was done in rolling bearing tests and gear tests. Their behaviour was compared for operating conditions in the range observable in a wind turbine gearbox.

The experimental results showed considerable differences between the different oils and it was observed that depending on the contact type the relative behaviour of the lubricants would change, i.e., the best lubricant for the rolling bearing would not imply the best result on the gear tests.

The gear geometry is also very important toward the transmission efficiency, once using a low loss gear concept a decrease of up to $25 \%$ in torque loss could be achieved.

Numerical models were implemented with the purpose of performing a better simulation of the mechanical system and also to obtain the friction coefficient promoted by the tested oils.
\end{abstract}

Keywords: gears; rolling bearings; friction coefficient; lubricants; efficiency

\section{Introduction}

The reduction of energy consumption and the improvement of equipment's life are the targets for any industry. The energy production using wind turbines is increasing at a fast pace and a large percentage of those machines use planetary gearboxes. Inside a planetary gearbox there are two main types of components dissipating energy: gears and bearing. These components efficiency is the main focus on this work.

The most common torque loss sources occurring within the gearbox are: friction loss between the meshing tooth [1-7], friction loss in the rolling bearings

* Corresponding author: Ramiro Carneiro MARTINS.

E-mail: rcm@fe.up.pt

A preliminary version of this work was presented at the 2nd International Brazilian Conference on Tribology-TriboBr-2014, Foz do Iguaçu, Paraná, Brazil, 2014.
$[1,8-11]$, load independent gear losses $[6,12-16]$ and energy loss due to air-drag [17].

The losses inside a gearbox have several side effects besides the immediate of increasing power consumption and one of the most important is the increment of the operating temperature of the oil. The increasing oil temperature might contribute to the increase of surface failure probability-wear, scuffing, micropitting or pitting, due to thinner film thickness and possible higher friction coefficient but, nevertheless, the additive package always plays a very important role [18].

ISO VG 320 is the oil viscosity specification for wind turbine gearboxes, but there are different formulations available that fulfil this viscosity specification, having quite different base oils. The most used base oils to formulate these lubricants are: mineral oil, PAO, ester and recently some PAG oils. These base oils have very different viscosity indexes and the typical oil 
temperature is between 60 to $80{ }^{\circ} \mathrm{C}$, but the viscosity specification is for $40{ }^{\circ} \mathrm{C}$. Another focus of this work is the analysis of the influence of different ISO VG 320 oils, taking into account their different viscosity, on the behaviour of bearings and gears.

\section{Material and methods}

\subsection{Lubricants}

Five commercial, fully formulated wind turbine gear oils were selected and characterized. The physical and chemical characterization of the lubricants is displayed in Table 1. The lubricants have these base oil: mineral (MINR), ester (ESTR), polyalphaolefin (PAOR), mineral with poly-alkyl-methacrylate thickener (MINE) and a poly-alkylene-glycol (PAGD).

All the lubricants are fully formulated gear oils and due to having different base oils they also have different additive packages. All lubricants comply with the requirements for wind turbine gearbox lubrication, besides all five products are premium products competing for market leadership.

\subsection{Rolling bearings test rig}

The rolling bearings tests were performed in a modified four-ball machine, where a new assembly to hold the

Table 1 Lubricant properties.

\begin{tabular}{|c|c|c|c|c|c|c|}
\hline Parameter & Unit & MINR & ESTR & PAOR & MINE & PAGD \\
\hline Base Oil & - & Mineral & 1 Ester & $\mathrm{PAO}$ & $\begin{array}{c}\text { Mineral } \\
+ \\
\text { PAMA }\end{array}$ & PAG \\
\hline \multicolumn{7}{|l|}{ Chemical composition } \\
\hline$\overline{Z i n c}(\mathrm{Zn})$ & ppm & 0.9 & 6.6 & 3.5 & $<1$ & 1 \\
\hline Magnesium (Mg) & ppm & 0.9 & 1.3 & 0.5 & $<1$ & 1.4 \\
\hline Posphorus (P) & ppm & 354.3 & 226.2 & 415.9 & 460 & 1,100 \\
\hline Calcium (Ca) & ppm & 2.5 & 14.4 & 0.5 & 2 & 0.8 \\
\hline Boron (B) & ppm & 22.3 & 1.7 & 28.4 & 36 & 1.0 \\
\hline Sulphur (S) & ppm & 11,200 & 406 & 5,020 & 6,750 & 362 \\
\hline \multicolumn{7}{|l|}{ Physical properties } \\
\hline Density @ $15^{\circ} \mathrm{C}$ & $\mathrm{g} / \mathrm{cm}^{3}$ & 0.902 & 0.915 & 0.859 & 0.893 & 1.059 \\
\hline Viscosity@40C & $\mathrm{cSt}$ & 319.2 & 302.9 & 313.5 & 328.3 & 290.3 \\
\hline Viscosity@80C & $\mathrm{cSt}$ & 43.9 & 56.1 & 60.4 & 66.5 & 78.9 \\
\hline Viscosity@100 들 & $\mathrm{cSt}$ & 22.3 & 34.9 & 33.3 & 37.1 & 51.1 \\
\hline $\begin{array}{l}\text { Piezoviscosity @ } 80{ }^{\circ} \mathrm{C} \\
\left(\alpha \times 10^{-8}\right)\end{array}$ & / & 1.68 & 1.14 & 1.28 & 1.26 & 1.05 \\
\hline Viscosity index & / & 85 & 162 & 149 & 163 & 241 \\
\hline $\mathrm{LP} @ 80^{\circ} \mathrm{C}\left(\mu \alpha 10^{11}\right)$ & $1 / \mathrm{s}$ & 66.5 & 58.5 & 66.4 & 74.8 & 87.3 \\
\hline
\end{tabular}

rolling bearings was installed together with a torque meter. The assembly has installed several thermocouples to measure operating temperatures and heaters to allow testing at controlled temperatures [10, 11, 19]. Figure 1 displays the schematic view of the rolling bearing assembly that allows testing thrust ball/cylindrical bearings on a four-ball machine. A detailed presentation of this assembly was made by Cousseau et al. [19].

The friction torque was measured with a piezoelectric torque cell KISTLER 9339A, ensuring high-accuracy measurements.

These tests were performed with bearing much smaller than the used in wind turbine gearboxes, nevertheless the operating conditions used were selected to be similar to the observed in wind turbine gearboxes.

\subsubsection{Bearings}

The rolling bearings geometry are presented in Table 2, as well as the load and contact pressure.

\subsubsection{Test procedure}

Two different bearings were tested, a thrust ball bearing (TBB) and a cylindrical roller thrust bearing (RTB) in order to promote an elliptical contact and a linear contact, respectively. The input speed used ranged from $75 \mathrm{rpm}$ till 1,200 rpm. The oil bath temperature was set to $80^{\circ} \mathrm{C}$.

\subsection{FZG test rig}

Figure 2 presents the FZG test machine used in this

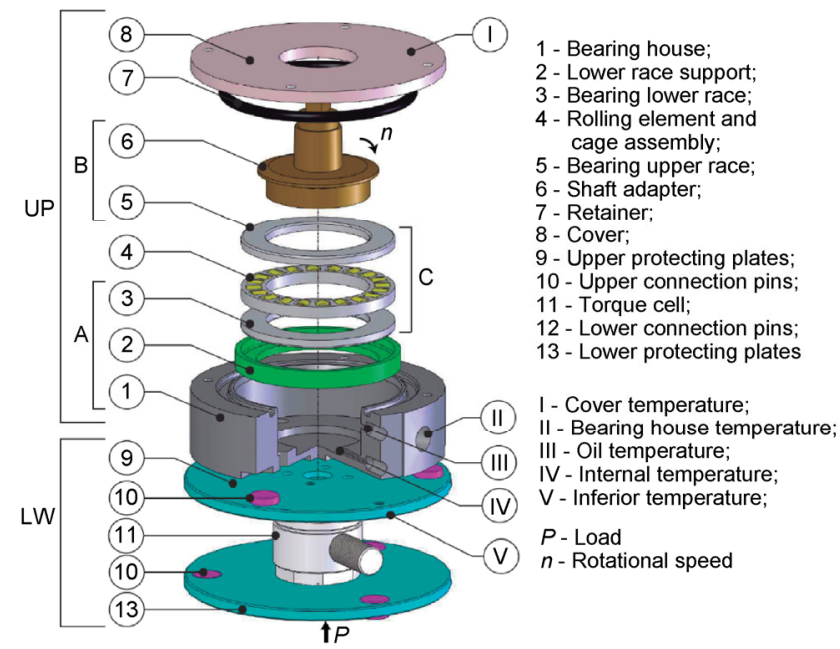

Fig. 1 Schematic view of the rolling bearing assembly used in the four-ball machine. 
Table 2 Bearings geometry and contact pressure for the two loads tested.

\begin{tabular}{ccccc}
\hline $\begin{array}{c}\text { Bearing type } \\
\text { Ref. }\end{array}$ & \multicolumn{2}{c}{ Thrust ball bearing } & \multicolumn{2}{c}{ Roller thrust bearing } \\
Bearing geometry & & & & \\
Contact element & raceway & ball & raceway & roller \\
$R_{\mathrm{xi}}(\mathrm{mm})$ & $\infty$ & 3 & $\infty$ & 5 \\
$R_{\mathrm{yi}}(\mathrm{mm})$ & 3.8 & 3 & $\infty$ & - \\
$L(\mathrm{~mm})$ & - & - & - & 5 \\
Load and pressure & & & & \\
\hline Load $(\mathrm{N})$ & 700 & 7000 & 700 & 7000 \\
Load ratio $(\mathrm{C} / \mathrm{P})(/)$ & 28.4 & 2.84 & 42 & 4.2 \\
$p_{\mathrm{H}}(\mathrm{GPa})$ & 1.15 & 2.48 & 0.32 & 1.0 \\
\hline
\end{tabular}
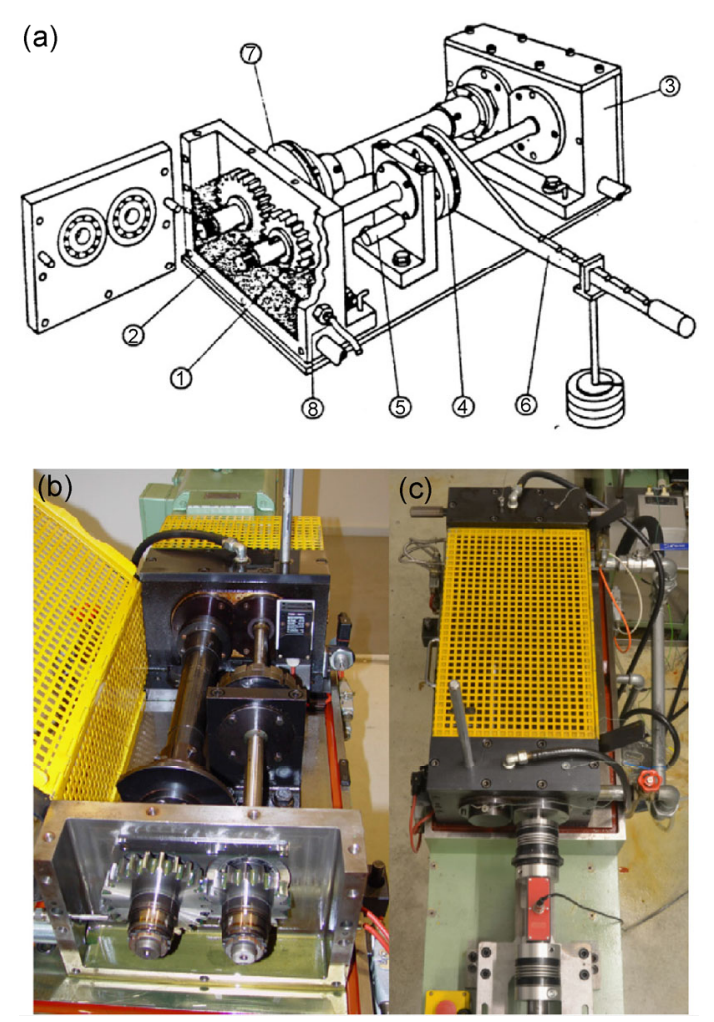

Fig. 2 FZG test rig. (a) Schematic view, (b) test gears, and (c) torque cell and drive gearbox [20].

work. The FZG machine is a gear test rig with circulating power [20]. The torque loss (TL) was measured using a torque transducer (ETH Messtechnik DRDL II) assembled on the FZG test machine, as shown schematically in Fig. 3.

The operating temperatures on eight different points of the assembly were also measured using thermocouples.

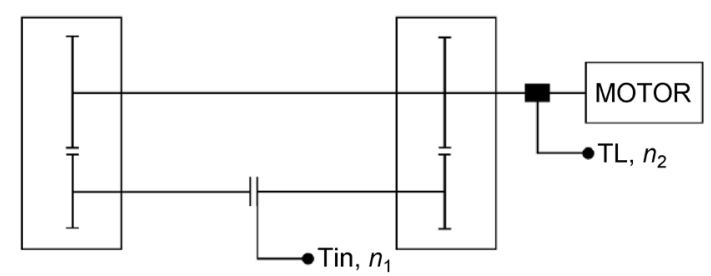

Fig. 3 Schematic representation of the FZG test rig with the input torque (Tin) and torque loss (TL) measured by the torque meter.

Two type of tests were performed: spur gear tests; helical gear tests with two different geometries.

\subsubsection{Test of spur gears-Type C 40}

The FZG spur gear tests were performed with type C gears having a face width of $40 \mathrm{~mm}$, usually assembled on FZG drive gearbox (closer to the electric motor). Table 3 displays the main geometric properties of the C40 spur gears used.

The same C40 gear set was used for testing all the lubricants. To assure that a similar surface finish was used with all lubricants, the C40 gear was run-in during 48 hours under dip lubrication with an ISO VG 150 PAO based gear oil.

The surface roughness was evaluated before and after the run-in period. There was, as expected a small decrease of the surface roughness and the surface roughness in the radial direction is considerably larger than that in the axial direction due to the grinding direction (axial). The average surface roughness in axial direction is $R_{\mathrm{a}}=0.35 \mu \mathrm{m}$ while in the radial direction is $R_{\mathrm{a}}=0.85 \mu \mathrm{m}$.

Both the test and the drive gearbox have four NJ406 cylindrical rolling bearings to support the shafts where the gears are assembled.

\subsubsection{Test of helical gears-Type H 501/Type H951}

To study the influence of the gear geometry on the power losses, and specially to prove the low loss gear design concept $[5,21-24]$, two gear geometries were used, both with a helix angle of $15^{\circ}$, but one with conventional addendum modifications (H501) and other aiming low losses (H951). The geometric properties of both gears are presented in Table 3.

For the test of helical gears a different test gearbox assembly must be used in comparison to the tests of C40 gears due to the axial forces promoted by the 
helical gears. The test gearbox has two NJ406 cylindrical rolling bearings and two QJ308 four point contact ball bearing, while the drive gearbox has the standard configuration with C40 spur gears and four NJ406 cylindrical rolling bearings.

\subsubsection{Test procedure}

The operating condition used in the FZG torque loss tests are presented in Table 4 . These operating conditions were used for both gear geometries. The tangential speed tested was selected to be close to the values found in some wind turbine gearboxes on their different multiplying stages.

The gearbox was lubricated by oil injection with a flow of $31 / \mathrm{min}$ at $80^{\circ} \mathrm{C}$.

The test procedure can be summarized as follows:

1. Run load stage $\mathrm{Ki}$ at each input speed condition
(Table 4) during $3 \mathrm{~h}$;

Continuous registry of the assembly working temperatures;

Continuous torque measurement.

2. Increase the load stage and repeat procedure till the highest load stage.

The values presented for torque loss and temperature are the average of the last 30 minutes of operation, i.e., only the steady state operating conditions are considered for the average calculation. All the system is cleaned with solvent before new oil testing.

\section{Results and discussion}

\subsection{Bearings}

Figures 4 and 5 display the measured torque loss as

Table 3 Geometrical properties of the test gears.

\begin{tabular}{|c|c|c|c|c|c|c|}
\hline \multirow{2}{*}{ Gear type } & \multicolumn{2}{|c|}{ Type C40 } & \multicolumn{2}{|c|}{ Type H501 } & \multicolumn{2}{|c|}{ Type H951 } \\
\hline & Pinion & Wheel & Pinion & Wheel & Pinion & Wheel \\
\hline Number of teeth & 16 & 24 & 20 & 30 & 38 & 57 \\
\hline Module (mm) & \multicolumn{2}{|c|}{4.5} & \multicolumn{2}{|c|}{3.5} & \multicolumn{2}{|c|}{1.75} \\
\hline Centre distance (mm) & \multicolumn{2}{|c|}{91.5} & \multicolumn{4}{|c|}{91.5} \\
\hline Pressure angle $\left(^{\circ}\right)$ & \multicolumn{2}{|c|}{20} & \multicolumn{4}{|c|}{20} \\
\hline Helix angle $\left(^{\circ}\right)$ & \multicolumn{2}{|c|}{0} & \multicolumn{4}{|c|}{15} \\
\hline Face width (mm) & \multicolumn{2}{|c|}{40} & \multicolumn{4}{|c|}{23} \\
\hline Addendum modification (/) & +0.1817 & +0.1715 & +0.1381 & +0.1319 & +1.6915 & +2.0003 \\
\hline Addendum diameter (mm) & 82.64 & 118.54 & 80.37 & 116.57 & 76.23 & 111.73 \\
\hline Transverse contact ratio $\epsilon_{\alpha}(/)$ & \multicolumn{2}{|c|}{1.44} & \multicolumn{2}{|c|}{1.45} & \multicolumn{2}{|c|}{0.93} \\
\hline Overlap contact ratio $\epsilon_{\beta}(/)$ & \multicolumn{2}{|c|}{0} & \multicolumn{2}{|c|}{0.54} & \multicolumn{2}{|c|}{1.08} \\
\hline Total contact ratio $\epsilon_{\gamma}(/)$ & \multicolumn{2}{|c|}{1.44} & \multicolumn{2}{|c|}{1.99} & \multicolumn{2}{|c|}{2.02} \\
\hline Material & \multicolumn{2}{|c|}{$20 \mathrm{Mn} \mathrm{Cr} 5$} & \multicolumn{4}{|c|}{$20 \mathrm{Mn} \mathrm{Cr} 5$} \\
\hline$R_{\mathrm{a}}(\mu \mathrm{m})$ & \multicolumn{2}{|c|}{0.9} & \multicolumn{4}{|c|}{0.3} \\
\hline
\end{tabular}

Table 4 Operating conditions on the FZG torque loss tests on spur and helical gear tests.

\begin{tabular}{|c|c|c|c|c|c|c|c|c|c|c|}
\hline \multirow[b]{3}{*}{ Load stage } & \multirow[b]{3}{*}{ Wheel torque } & \multicolumn{3}{|c|}{ Wheel Speed (rpm) } & & & & & & \\
\hline & & 200 & 400 & 1200 & \multicolumn{3}{|c|}{ Spur C40 } & \multicolumn{3}{|c|}{ Helical H501/951 } \\
\hline & & & Input power & & $\mathrm{Fr}$ & $\mathrm{Fa}$ & $p_{\mathrm{H}}$ & $\mathrm{Fr}$ & $\mathrm{Fa}$ & $p_{\mathrm{H}}$ \\
\hline $\mathrm{Ki}$ & $(\mathrm{N} \cdot \mathrm{m})$ & & $(W)$ & & $(\mathrm{N})$ & $(\mathrm{N})$ & $(\mathrm{MPa})$ & $(\mathrm{N})$ & $(\mathrm{N})$ & $(\mathrm{MPa})$ \\
\hline $\mathrm{K} 1$ & 4.95 & 104 & 207 & 622 & 37 & 0 & 108 & 37 & 24 & 171 \\
\hline K5 & 104.97 & 2,198 & 4,397 & 13,191 & 790 & 0 & 498 & 777 & 518 & 787 \\
\hline K7 & 198.68 & 4,161 & 8,322 & 24,967 & 1,495 & 0 & 685 & 1,471 & 980 & 1,083 \\
\hline K9 & 323.27 & 6,771 & 13,541 & 40,623 & 2,432 & 0 & 874 & 2,393 & 1,594 & 1,382 \\
\hline
\end{tabular}




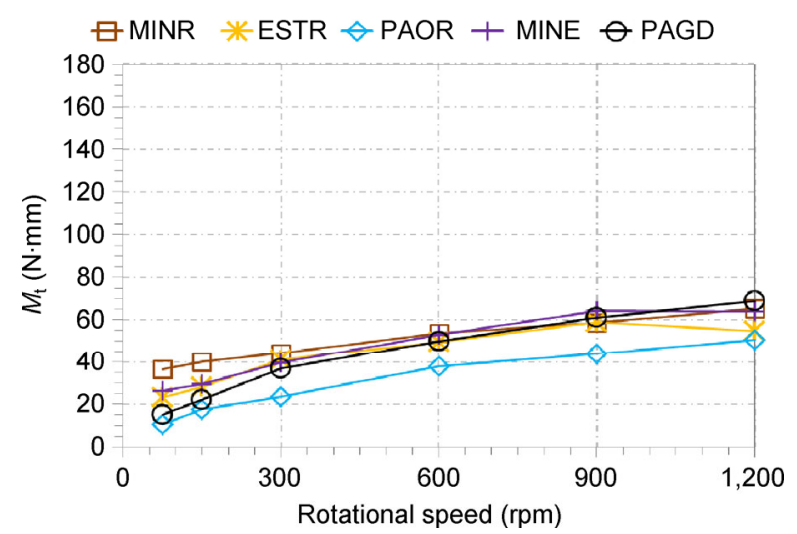

Fig. 4 Torque loss of TBB for a load of $700 \mathrm{~N}$.

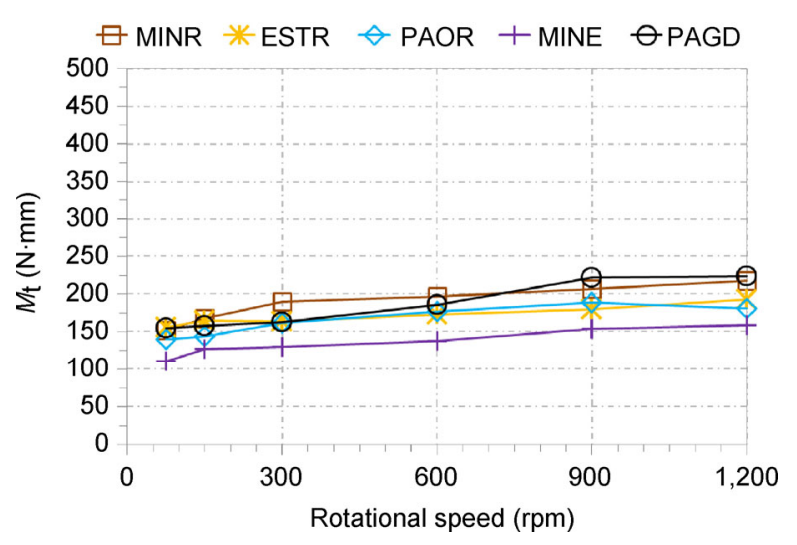

Fig. 5 Torque loss of TBB for a load of 7,000 N.

function of the input speed on the thrust ball bearing (TBB) for the loads of 700 and 7,000 N, respectively. The torque loss increased with the increasing speed, and increasing the load ten times, roughly it triples the torque loss.

Figures 6 and 7 display the torque loss for the cylindrical roller thrust bearings (RTB) as function of speed and for the loads of 700 and $7,000 \mathrm{~N}$, respectively. The tests performed at 1,200 rpm and $7,000 \mathrm{~N}$ had an oil bath temperature slightly higher than $80^{\circ} \mathrm{C}$. For the load of $700 \mathrm{~N}$ the torque loss increases with the speed, but for the load of $7,000 \mathrm{~N}$, a decrease of the torque loss is observed for the majority of the lubricants.

\subsubsection{Discussion}

The TBB results show that the PAOR had the lowest torque loss for the load of $700 \mathrm{~N}$ and MINE had the lowest torque loss for a load of 7,000 N.

For RTB tests there are significant changes on the lubricants behaviour when the load increases from

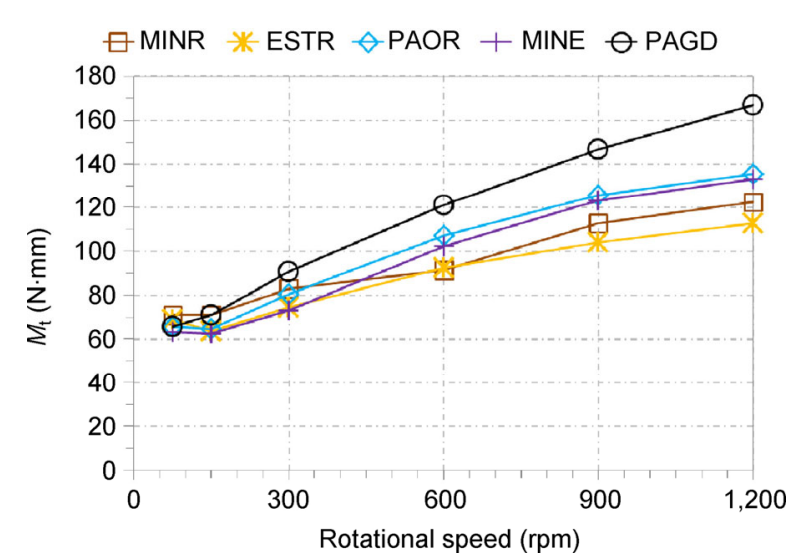

Fig. 6 Torque loss of RTB for a load of $700 \mathrm{~N}$.

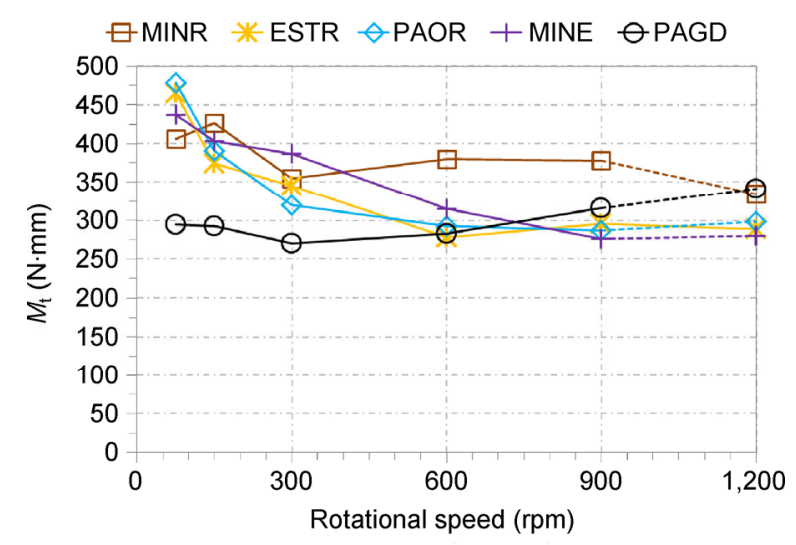

Fig. 7 Torque loss of RTB for a load of 7,000 N.

700 to $7,000 \mathrm{~N}$. For the load of $700 \mathrm{~N}$ the PAGD lubricant displays the largest toque loss while the MINR and ESTR had the lowest result that appears to be driven by lubricants viscosity. For the load of $7,000 \mathrm{~N}$ the PAGD lubricant had the lowest torque loss for the lower speeds while the mineral bases had the highest.

The relative behaviour of the lubricants is dependent on the bearing type, being the sliding speed the biggest difference between the TBB and the RTB, and also the contact pressure.

Figures 8 and 9 display the specific film thickness calculated for the tests performed for TBB and RTB, respectively. The centre film thickness in the rollerraceway contact of the RTB was determined using the Dowson and Higginson [25] equation for rectangular contacts and the centre film thickness in the ballraceway contact of the BTB was determined using the Hamrock and Dowson [26] equation for elliptical contacts, both corrected with the thermal reduction factor due to inlet shear heating proposed by Gupta et al. [27]. 


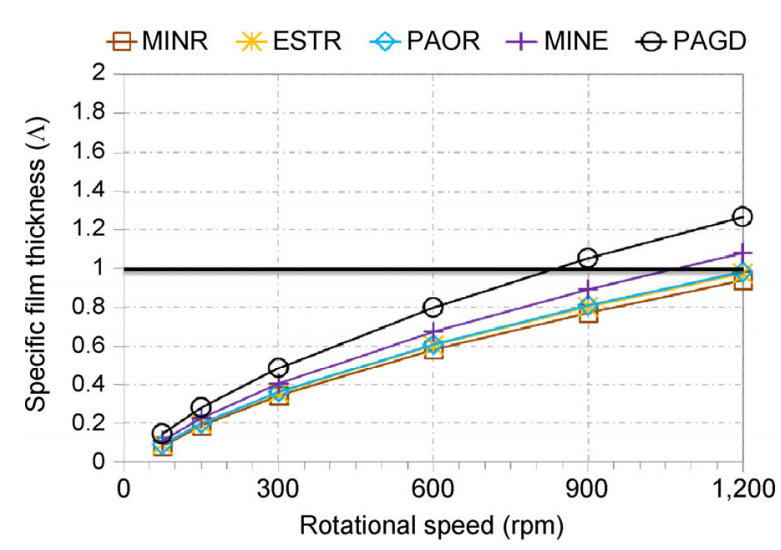

Fig. 8 Specific film thickness for TBB bearing with an applied load of 7,000 N.

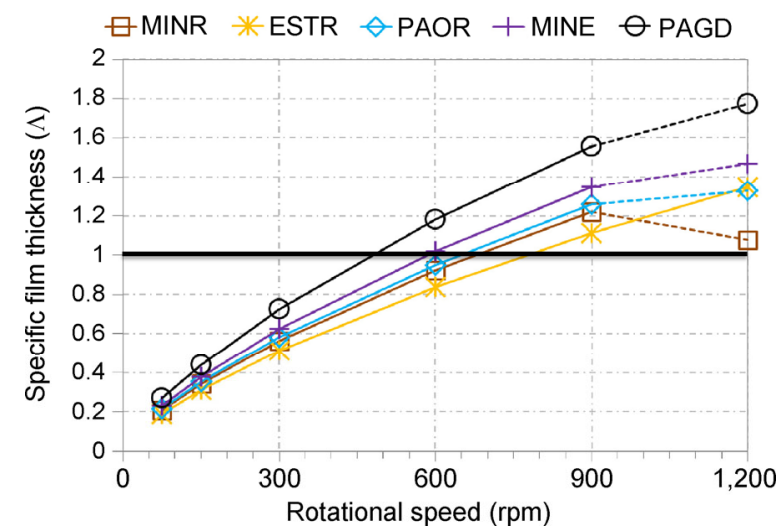

Fig. 9 Specific film thickness for RTB bearing with an applied load of 7,000 N.

The first fact to be noticed is that TBB tests were performed under boundary lubrication regime, while for the RTB half of the tests were performed in boundary and half in mixed lubrication regime.

To have a better understanding of these results, the SKF model for bearings was used, although the results were not consistent for the lower speeds with the model predicting much higher torque loss than measured. The model was already used on these bearings without imposing an oil bath temperature and the results were very good, so it appears that the operating temperature is higher than the stabilization temperature, i.e., a thinner lubricant film changes the model prediction.

The rolling torque has a very low dependence on the load, so the biggest impact of the load is on the sliding torque (the boundary conditions are considered on it), so a correction to the bearings sliding torque was implemented, please see Fernandes et al. [10, 11] for further details. The model calculation is now in good agreement with the experimental results.

Figures 10 and 11 display the sliding torque as function of speed for the load of 7,000 $\mathrm{N}$ for the TBB and RTB bearing, respectively. The sliding torque on the thrust ball bearing (TBB) is almost constant with the increasing speed while for the cylindrical thrust roller bearing (RTB) the sliding torque decreases substantially. The low specific film thickness has a much higher influence on the RTB than on the TBB that should be due to the high sliding speed that happens in the cylindrical thrust roller bearings.

\subsection{FZG gears}

\subsubsection{Spur gears type C40}

Figure 12 displays the torque loss (TL) measurements for all the lubricants and test conditions. The load stage $\mathrm{K} 1$ was performed to gather knowledge about the no-load operating conditions, i.e., the load independent losses.

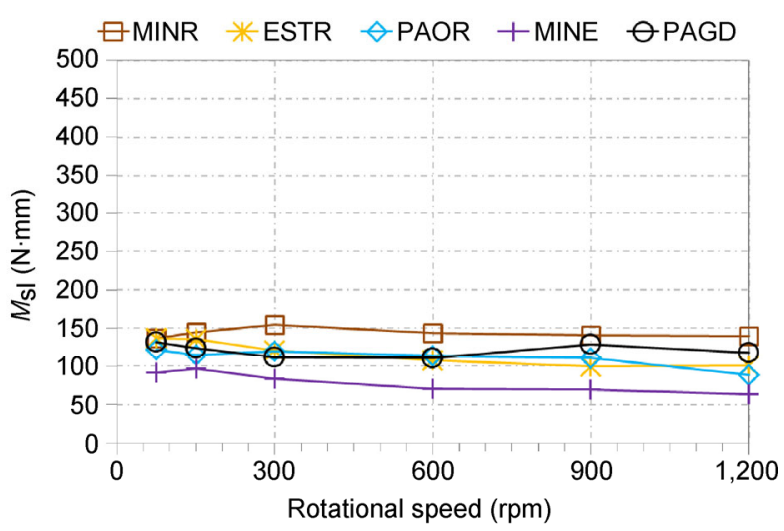

Fig. 10 Sliding torque for TBB bearing with an applied load of $7,000 \mathrm{~N}$.

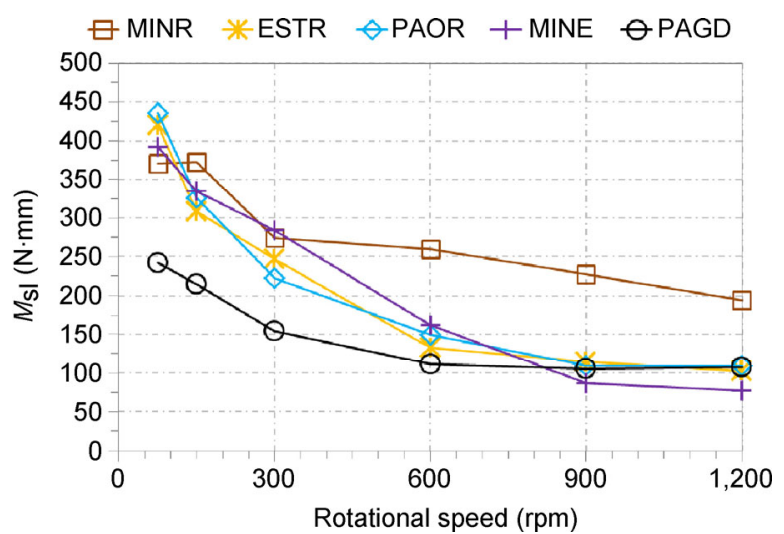

Fig. 11 Sliding torque for RTB bearing with an applied load of $7,000 \mathrm{~N}$. 

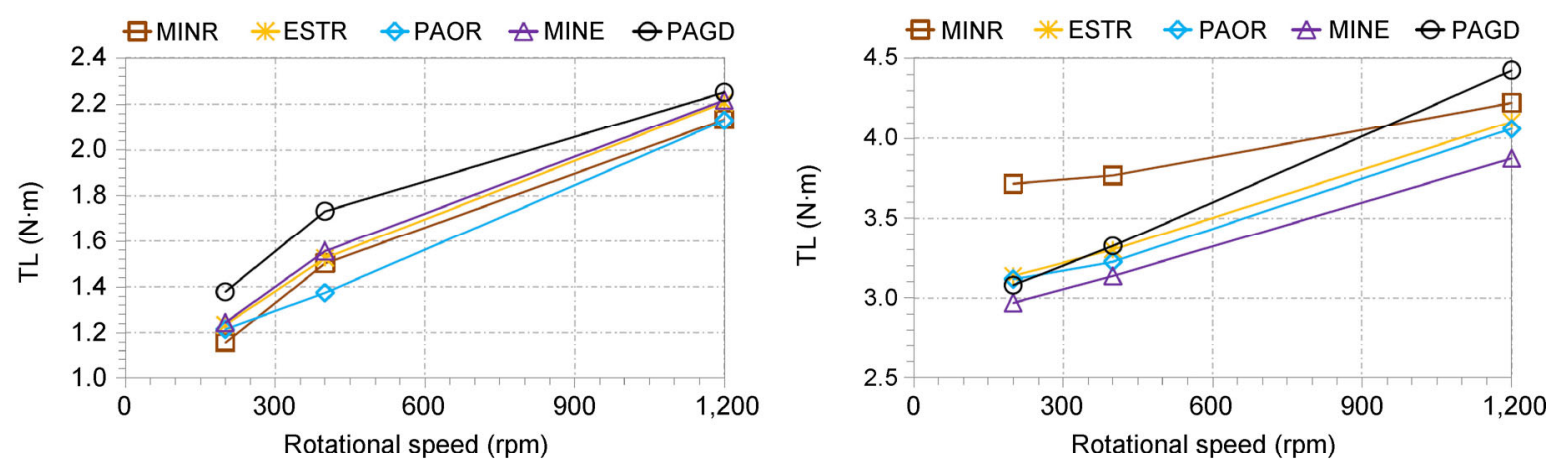

K1
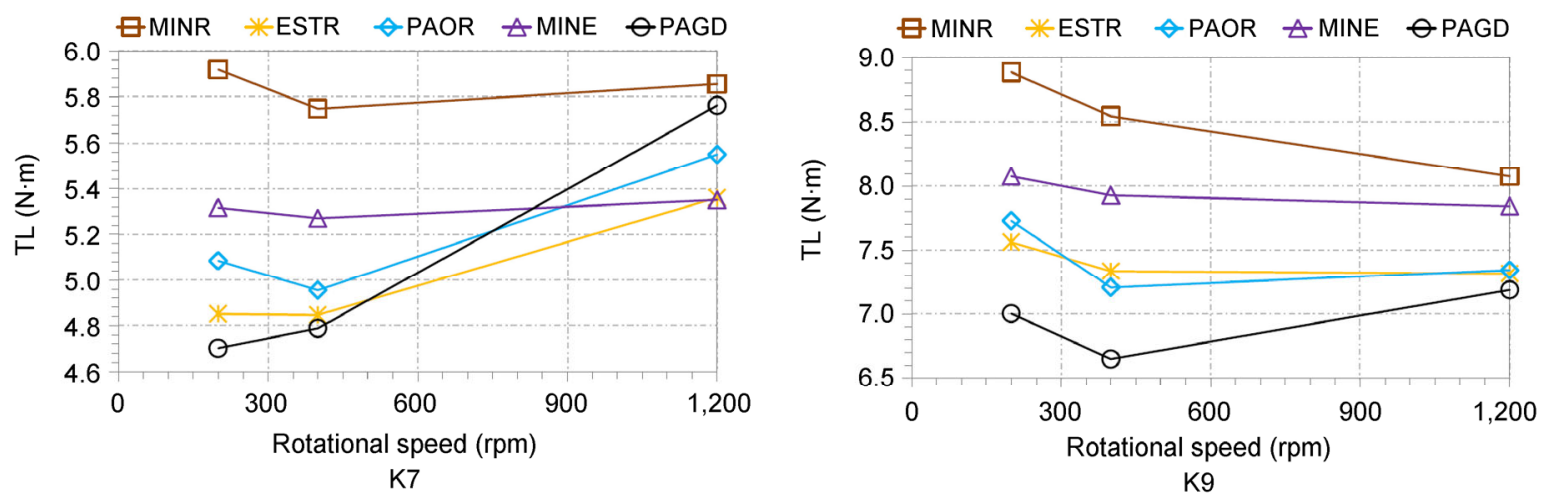

Fig. 12 Evolution of torque loss with speed for each load stage and for each lubricant with spur gears C40.

For the load stages K1 and K5 the lubricants ESTR, PAOR and MINE have similar torque losses, while PAGD and MINR have the higher torque losses. However with the increasing load the PAGD torque loss decreases and exhibits the lowest torque loss, especially for lowest speeds. The experimental results somehow resemble a Stribeck curve with a minimum value of torque loss under mixed lubrication. The minimum value of torque loss took place at different speeds, as function of the oil.

\subsubsection{Helical gears type H 501/H951}

The experimental torque loss measurements with helical gears H501 and H951 are presented in Fig. 13 as function of input load and speed. Figure 13 clearly shows that the helical gear geometry $\mathrm{H} 951$ has lower torque loss than the H501 gear geometry and this difference increases with the increasing load. Unfortunately the MINE tests with H951 geometry couldn't be finished due to a test rig failure.

\subsubsection{Discussion}

The torque loss tests were performed with a constant oil operating temperature of $80^{\circ} \mathrm{C}$. The viscosity at
$80{ }^{\circ} \mathrm{C}$ for each lubricant is displayed in Table 1, with the PAGD having the highest viscosity, the PAOR, ESTR and MINE having similar viscosities and the MINR having the lowest viscosity. For the formation of lubricant film at high pressure (inside the contact) the piezoviscosity is also of fundamental importance, and their relative value is the opposite of the observed for viscosity at environment pressure (as displayed in Table 1). The lubricant parameter [28] reflects the influence of oil's viscosity and piezoviscosity in the film formation capabilities and is also represented in Table 1.

The results displayed for load stage K1 show some dependence of the torque loss on the operating viscosity for both spur and helical gears, although the highest differences between lubricants are noticed for high loads and high speeds.

For the C40 spur gears the observation of the results at constant load with decreasing speed shows that the torque loss decreases with decreasing speed up to load stage $\mathrm{K} 7$, where at $400 \mathrm{rpm}$ it is observed a stabilization/increase of the torque loss indicating an increase of the friction losses in the contact, once the churning losses decrease with the decreasing speed. 

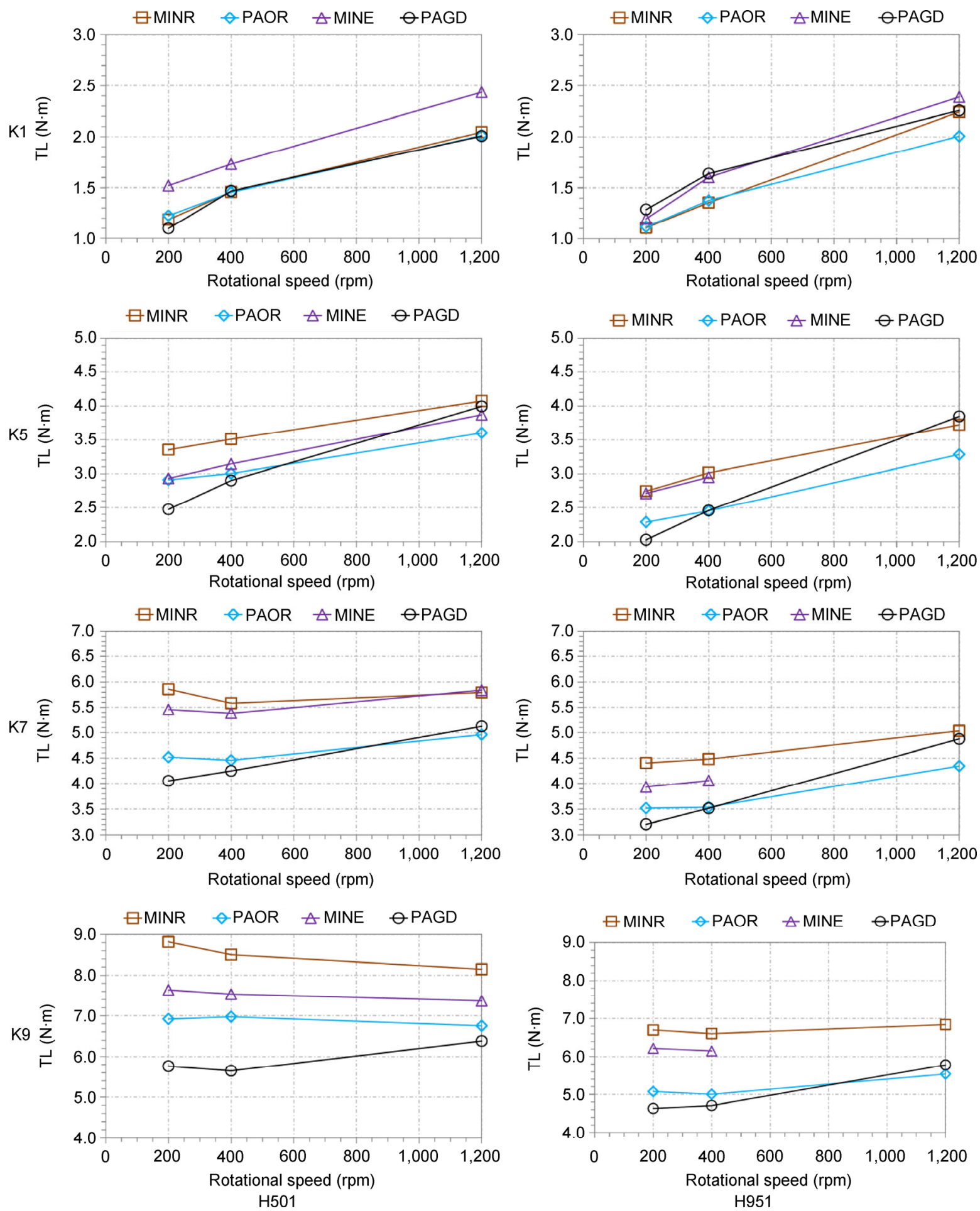

Fig. 13 Evolution of torque loss with speed for each load stage and for each lubricant with helical gears H501 and H951.

This inflexion of behavior has different changing rates, with the MINR and MINE displaying almost constant torque loss between 1,200 and $400 \mathrm{rpm}$ and a slight increase for $200 \mathrm{rpm}$, while the synthetic base lubricants display a large decrease of torque loss with the decrease of speed, i.e., a smaller increase of friction with the decrease of speed. The PAGD lubricant only shows this inflexion point on load stage K9 at $400 \mathrm{rpm}$. 
This behavior resembles a Stribeck curve with indication of the minimum torque loss for a certain speed and load, depending on the lubricant.

For the spur gears at high load the PAGD displayed the lowest torque loss, followed by the PAOR and ESTF that displayed quite similar results. The MINE presented a torque loss in between the PAOR/ESTR and the MINR, with the MINR displaying the largest torque loss. For MINR and MINE at load stage K9, the decrease of speed promotes the increase of torque loss while for PAGD, PAOR and ESTR the minimum torque loss takes place for $400 \mathrm{rpm}$.

For the helical gears H501 the behavior is quite similar to the observed for the C40 gears.

For the helical gears H951 the measured torque loss decreases with the decrease of speed for all the loads tested, indicating that the minimum torque loss or the inflexion point was not reached for the tested operating conditions, i.e., the increase of friction losses was not higher than the decrease of churning losses. Once, with the decrease of speed, the churning losses decrease and the load dependent losses should increase (at constant load) due to the lower film thickness.

In general, the relative behavior of the lubricants is similar whatever the gear geometry. The PAGD lubricant always displays the lowest torque loss at low speed and high load and this should be due to its highest viscosity, although the highest viscosity has a drawback when the speed increases and the torque loss has a higher increase with the increase of speed than the observed for the other lubricants.

When comparing the gear geometries, it is observed that the spur and $\mathrm{H} 501$ gears have quite similar results but the H951 geometry, designed to promote low losses, displays much smaller torque losses, in fact the reduction in torque losses can reach up to $25 \%$, as observed in Fig. 13.

\section{Power loss numerical model}

To extend the comprehension of the experimental results presented and to allow the forecast of power losses in a transmission, a numerical model has been developed and implemented to calculate the different forms of torque loss inside a gearbox for different operating conditions, gear geometries and different lubricants [5, 10, 11, 23, 29-34].

Figure 14 displays an equation including all the sources of power losses in a gear transmission. There are power losses dependent on load and also no-load dependent power losses. This division is usually made for gears and bearings. The equations mainly states that the total power losses $\left(P_{\mathrm{V}}\right)$ are the sum of: gear no-load losses $\left(P_{\mathrm{Vz} 0}\right)$; load dependent losses gear losses $\left(P_{\mathrm{VZP}}\right)$; bearings losses $\left(P_{\mathrm{VL}}\right)$; seal losses $\left(P_{\mathrm{VD}}\right)$ and some eventual auxiliary losses.

The main focus on this work was gears and bearings losses, being those characterized for each lubricant, gear geometry and rolling bearing used in order to do an accurate fit of the experimental results gathered and to allow a forecasting of power losses for different operating conditions and gear/bearing geometries.

Fernades et al. [30-32] detailed the numerical model and the calculation procedure, so only some remarks will be presented in this work.

\subsection{Bearing power losses}

The bearings power losses were calculated using the SKF numerical model [8]. The results presented above allowed the determination of the two coefficients of friction that are lubricant dependent for linear and elliptical contacts, i.e., roller thrust bearing (RTB) and thrust ball bearings (TBB), respectively.

The total torque loss measured $\left(M_{\exp }\right)$ is the sum of the sliding torque $\left(M_{\mathrm{sl}}\right)$ and rolling torque $\left(M_{\mathrm{rr}}^{\prime}\right)$, once the rolling bearings do not have seals and the drag losses can be disregarded (Eq. 1). The rolling torque is only a function of geometry speed and viscosity and can be determined according to Eq. 2 .

The sliding torque is calculated according to Eq. 3, but it is a function of the sliding friction coefficient $\left(\mu_{\mathrm{sl}}\right)$. So, to determine the sliding friction coefficient,

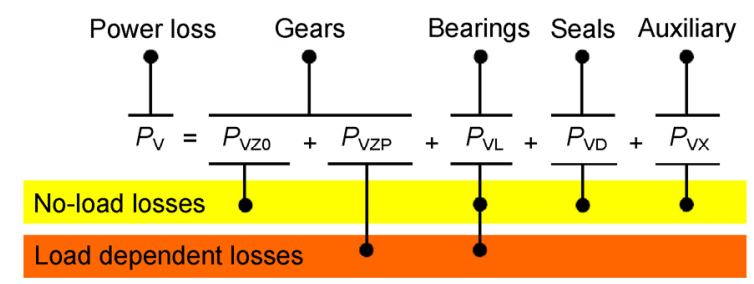

Fig. 14 Sources of power losses in a transmission [35]. 
the sliding torque is calculated according to Eq. 4 . The experimental sliding friction coefficient can be determined using Eq. 3. According to SKF, the sliding friction coefficient is a function of the boundary friction coefficient $\left(\mu_{\mathrm{bl}}\right)$ and the full film friction coefficient $\left(\mu_{\mathrm{EHD}}\right)$ and a weighing factor $\left(\Phi_{\mathrm{bl}}\right)$ is used, as represented in Eq. 5. This procedure was detailed by Fernandes et al. [33].

$$
\begin{gathered}
M_{\mathrm{exp}}=M_{\mathrm{t}}=M_{\mathrm{rr}}^{\prime}+M_{\mathrm{sl}} \\
M_{\mathrm{rr}}=\phi_{\mathrm{ish}} \cdot \phi_{\mathrm{rs}}\left[G_{\mathrm{rr}}(n \cdot v)^{0.6}\right] \\
M_{\mathrm{sl}}=G_{\mathrm{sl}} \cdot \mu_{\mathrm{sl}} \\
M_{\mathrm{sl}}=M_{\mathrm{t}}-M_{\mathrm{rr}}^{\prime}=M_{\mathrm{exp}}-M_{\mathrm{rr}}^{\prime} \\
\mu_{\mathrm{sl}}=\phi_{\mathrm{bl}} \cdot \mu_{\mathrm{bl}}+\left(1-\phi_{\mathrm{bl}}\right) \cdot \mu_{\mathrm{EHD}}
\end{gathered}
$$

Table 5 displays the value of each coefficient of friction for each oil tested, obtained with the experimental results displayed (considering the oil temperature of the experimental tests). These coefficients of friction, for each oil tested, allow the determination of the bearings power losses for different bearing sizes and geometries with much better accuracy.

\subsection{Gears power losses}

The numerical determination of the gears power losses were performed according to Höhn et al. [1]. On this formulation special attention must be paid to the gear loss factor $\left(H_{\mathrm{V}}\right)$ once this is the factor that distinguishes the different gear geometries. The load

Table 5 Boundary $\left(\mu_{\mathrm{bl}}\right)$ and EHD $\left(\mu_{\mathrm{EHL}}\right)$ coefficient of friction for TBB and RTB bearings at $80^{\circ} \mathrm{C}$.

\begin{tabular}{cccc}
\hline & Bearing type & TBB & RTB \\
\hline MINR & $\mu_{\mathrm{bl}}$ & 0.058 & 0.035 \\
& $\mu_{\mathrm{EHD}}$ & 0.056 & 0.018 \\
\hline ESTR & $\mu_{\mathrm{bl}}$ & 0.060 & 0.040 \\
& $\mu_{\mathrm{EHD}}$ & 0.043 & 0.010 \\
\hline PAOR & $\mu_{\mathrm{bl}}$ & 0.049 & 0.039 \\
& $\mu_{\mathrm{EHD}}$ & 0.044 & 0.010 \\
\hline \multirow{2}{*}{ MINE } & $\mu_{\mathrm{bl}}$ & 0.044 & 0.044 \\
& $\mu_{\mathrm{EHD}}$ & 0.027 & 0.008 \\
\hline \multirow{2}{*}{ PAGD } & $\mu_{\mathrm{bl}}$ & 0.054 & 0.025 \\
& $\mu_{\mathrm{EHD}}$ & 0.044 & 0.010 \\
\hline
\end{tabular}

dependent power losses on the gears $\left(P_{\mathrm{VZP}}\right)$ are calculated according to Eq. 6 . The gear loss factor is calculated according to Eq. 7 and is also dependent on the load distribution along the path of contact, especially for the helical gears. The average friction coefficient between teeth contact is determined according to Eq. 8 that is dependent on the lubricant parameter $\left(X_{\mathrm{L}}\right)$. The lubricant parameter $\left(X_{\mathrm{L}}\right)$ is the parameter that translates the influence of the lubricant on the gear friction. $X_{\mathrm{L}}$ was obtained through the experimental tests presented.

$$
\begin{gathered}
P_{\mathrm{VZP}}=P_{\mathrm{IN}} \cdot H_{\mathrm{V}} \cdot \mu \\
H_{\mathrm{V}}^{\text {num }}=\frac{1}{p_{\mathrm{b}}} \int_{0}^{b} \int_{A}^{E} \frac{F_{\mathrm{N}}(x, y)}{F_{\mathrm{b}}} \cdot \frac{V_{\mathrm{g}}(x, y)}{V_{\mathrm{b}}} \mathrm{d} x \mathrm{~d} y \\
\mu_{\mathrm{mZ}}=0.048\left(\frac{F_{\mathrm{bt}} / b}{v_{\Sigma \mathrm{C}} \cdot \rho_{\mathrm{redC}}}\right)^{0.2} \eta^{-0.05} \cdot R_{\mathrm{a}}^{0.25} \cdot X_{\mathrm{L}}
\end{gathered}
$$

Table 6 displays the lubricant parameter calculated for the oils tested. With this parameter it is now possible to calculate the average friction coefficient for different operating conditions.

Figure 15 displays the comparison of the experimental power losses with the numerical model results obtained for the PAOR lubricant, showing an excellent correlation (>99.5\%) and allowing to distinguish between gear geometries and lubricant for different operating conditions. Attention must be paid to the validity of the determined parameters that is only inside the operating conditions tested. This figure shows that the numerical model works very well even with an unusual gear geometry such as H951.

Table 6 Lubricant parameter determined for the oils tested.

\begin{tabular}{cc}
\hline Oil & $X_{L}$ \\
\hline MINR & 0.89 \\
PAOR & 0.65 \\
ESTR & 0.63 \\
MINE & $0.5\left(\frac{F_{\mathrm{bt}} / b}{v_{\Sigma \mathrm{C}} \cdot \rho_{\mathrm{redc}}}\right)^{0.1}$ \\
PAGD & $0.5\left(\frac{F_{\mathrm{bt}} / b}{v_{\Sigma \mathrm{C}} \cdot \rho_{\mathrm{red}}}\right)^{0.05}$ \\
\hline
\end{tabular}



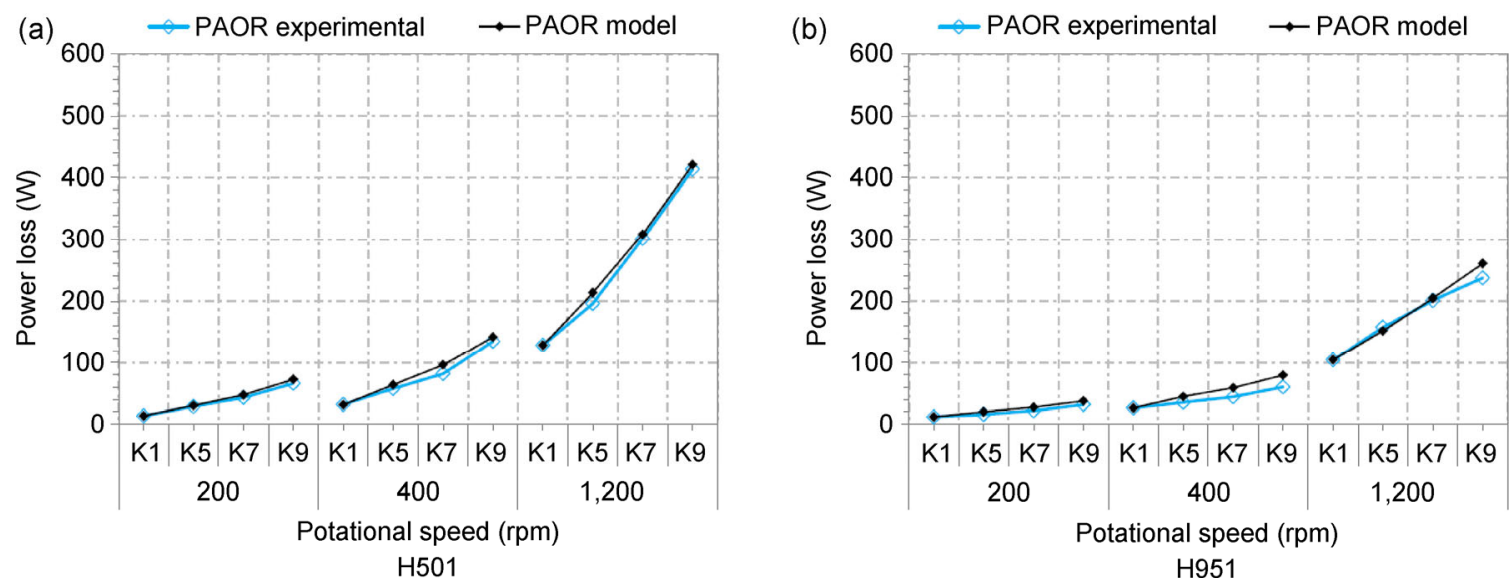

Fig. 15 Comparison of the experimental power losses with the numerical results obtained with the numerical model for the PAOR lubricant.

\section{Conclusion}

The main conclusions that can be draw from this work are:

- The viscosity at typical operating temperature of the wind turbine gear oils has a huge difference, with implications on the components behaviour.

- The MINR (lowest viscosity at operating temperature) in general had the highest torque loss with both bearings and all gears for high load and low speed operating conditions.

- The PAGD (highest viscosity at operating temperature) had a very good behaviour for the high load conditions and low speed.

- The PAOR, ESTR and MINE had in general very good and similar behaviour.

- Fully formulated gear oils have quite different behaviour.

- The H951 gear geometry promotes a reduction on the total torque loss up to $25 \%$ when compared the H501 gear geometry.

- Combining the lubricant with best behaviour (PAGD) with the geometry with best behaviour (H951) the global efficiency of the transmission can increase up to $1 \%$.

- After appropriate rolling bearings and gear tests the power losses in a gearbox can be accurately predicted for different operating conditions and different geometry.

- The selection of the best lubricant and best gear geometry can promote a substantial reduction on the operation cost of a gear transmission.

\section{Acknowledgments}

This work was funded by national funds through FCT_Fundação para a Ciência e a Tecnologia within the project EXCL/EMS-PRO/0103/2012. This work was co-funded by COMPETE, QREN, and EU.

Open Access: This article is distributed under the terms of the Creative Commons Attribution Noncommercial License which permits any noncommercial use, distribution, and reproduction in any medium, provided the original author(s) and source are credited.

\section{References}

[1] Höhn B-R, Michaelis K, Vollmer T. Thermal rating of gear drives: Balance between power loss and heat dissipation. AGMA Technical Paper, 1996.

[2] Martins R, Cardoso N, Seabra J. Gear power loss performance of biodegradable low-toxicity ester-based oils. Proc IMechE, Part J: J Eng Tribol 222(J3): 431-440 (2008)

[3] Martins R, Seabra J, Brito A, Seyfert C, Luther R, Igartua A. Friction coefficient in FZG gears lubricated with industrial gear oils: Biodegradable ester vs. mineral oil. Tribol Int 39(6): 512-521 (2006)

[4] Martins R C, Moura P S, Seabra J O. Power loss in FZG gears: Mineral oil vs. biodegradable ester and carburized steel vs. austempered ductile iron vs. $\mathrm{MoS}_{2}$-Ti coated steel. In International Conference on Gears, 2005: 1467-1486.

[5] Magalhães L, Martins R, Locateli C, Seabra J. Influence of tooth profile and oil formulation on gear power loss. Tribol Int 43(10): 1861-1871 (2010)

[6] Marques P M T, Fernandes C M C G, Martins R C, Seabra J $\mathrm{H}$ O. Power losses at low speed in a gearbox lubricated with 
wind turbine gear oils with special focus on churning losses. Tribol Int 62:186-197 (2013)

[7] Martins R C, Cardoso N F R, Bock H, Igartua A, Seabra J $\mathrm{H}$ O. Power loss performance of high pressure nitrided steel gears. Tribol Int 42(11-12): 1807-1815 (2009)

[8] SKF General Catalogue 6000 EN: SKF, 2005.

[9] Eschmann P, Hasbargen L, Weigand K. Ball and Roller Bearings-Theory, Design, and Application. KgaA F K G S Ed. John Wiley and Sons, 1985.

[10] Fernandes C M C G, Martins R C, Seabra J H O. Friction torque of cylindrical roller thrust bearings lubricated with wind turbine gear oils. Tribol Int 59:121-128 (2013)

[11] Fernandes C M C G, Martins R C, Seabra J H O. Friction torque of thrust ball bearings lubricated with wind turbine gear oils. Tribol Int 58: 47-54 (2013)

[12] Ariura Y, Ueno T. The lubricant churning loss and its behavior in gearbox in cylindical gear systems. J Jpn Soc Lubr Eng 20 (1975)

[13] Mauz W. Hydraulische Verlute von Stirnradgetrieben bei Umfangsgeschwindigkeiten bis $60 \mathrm{~m} / \mathrm{s}$. Ph.D. Thesis. Stutgart University, 1987.

[14] Maurer J. Ventilationsverluste. FVA Forschungsvorhaben $\mathrm{Nr}$ 44/VI, 1994.

[15] Changenet C, Velex P. A model for the prediction of churning losses in geared transmissions-Preliminary results. $J$ Mech Des 129(1): 128-133 (2007)

[16] Changenet C, Leprince G, Ville F, Velex P. A Note on flow regimes and churning loss modeling. $J$ Mech Des 133(12): 121009 (2011)

[17] Csoban A, Kozma M. Tooth friction loss in simple planetary gears. In 7th International Multidisciplinary Conference, 2007: 153-160.

[18] Hohn B R, Michaelis K. Influence of oil temperature on gear failures. Tribol Int 37(2):103-109 (2004)

[19] Cousseau T, Graça B, Campos A, Seabra J. Friction torque in grease lubricated thrust ball bearings. Tribol Int 44(5): 523-531 (2011)

[20] Winter H, Michaelis K. FZG gear test rig-Desciption and possibilities. In Coordinate European Council: Second International Symposium on the Performance Evaluation of Automotive Fuels and Lubricants, 1985.

[21] Höhn B R, Michaelis K, Wimmer A. Low loss gears. Gear Technol 24(4): 28-35 (2007)

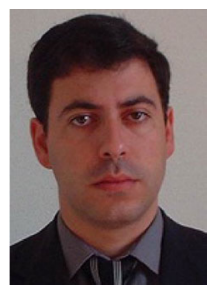

Ramiro Carneiro MARTINS. He received his Ph.D. degree in mechanical engineering from Universidade do Porto, Portugal in 2008. He joined INEGI Research Institute in 2001 and
[22] Magalhaes L, Martins R, Locateli C, Seabra J. Influence of tooth profile on gear power loss. Ind Lubr Tribol (1): 1-10 (2011)

[23] Magalhães L, Martins R, Oliveira I, Seabra J. Comparison of tooth profiles and oil formulation focusing lower power losses. Proc IMechE, Part J: J Eng Tribol 226(6): 529-540 (2012)

[24] Magalhães L, Martins R, Seabra J. Low-loss austempered ductile iron gears: Experimental evaluation comparing materials and lubricants. Tribol Int 46(1): 97-105 (2012)

[25] Dowson D, Higginson G R. Elastohydrodynamic Lubrication. Oxford: Pergamon Press, 1977.

[26] Hamrock B J, Dowson D. Ball Bearing Lubrication, the Elastohydrodynamics of Elliptical Contacts. New York: Willey, 1981.

[27] Gupta P K, Cheng H S, Zhu D, Forster N H, Schrand J B. Viscoelastic effects in mill-7808-type lubricant. Part I. Analytical formulation. Tribol Trans 35(2): 269-274 (1992)

[28] Kotzalas M. Chapter 9. Rolling contact fatigue wear. In $C R C$ Handbook of Lubrication: Theory and Practice of Tribology, Volume II: Theory and Design. Bruce R W Ed. CRC Press, 2010.

[29] Marques P M T, Fernandes C M C G, Martins R C, Seabra J $\mathrm{H}$ O. Efficiency of a gearbox lubricated with wind turbine gear oils. Tribol Int 71: 7-16 (2014)

[30] Fernandes C M C G, Martins R C, Seabra J H O. Torque loss of type C40 FZG gears lubricated with wind turbine gear oils. Tribol Int 70: 83-93 (2014)

[31] Fernandes C M C G, Amaro P M P, Martins R C, Seabra J $\mathrm{H}$ O. Torque loss in thrust ball bearings lubricated with wind turbine gear oils at constant temperature. Tribol Int 66: 194-202 (2013)

[32] Fernandes C M C G, Amaro P M P, Martins R C, Seabra J $\mathrm{H}$ O. Torque loss in cylindrical roller thrust bearings lubricated with wind turbine gear oils at constant temperature. Tribol Int 67: 72-80 (2013)

[33] Martins R C, Seabra J H O, Ruis-Moron L F. Influence of oil formulation on gear micropitting and power loss performance. Proc IMechE, Part J: J Eng Tribol 225(6): 429-439 (2011)

[34] Martins R C, Seabra J H O, Moron L F. Influence of PAO plus ester oil formulations on gear micropitting and efficiency. Int J Surf Sci Eng 5(4): 312-329 (2011)

[35] Höhn B-R, Michaelis K, Hinterstoißer M. Optimization of gearbox efficiency. Goriva i maziva 48(4): 441-480 (2009)

his current position is senior researcher. His research interests include pitting and micropitting fatigue, friction in lubricated contacts, lubricants properties, contact mechanics and gears and rolling bearings testing. 